\title{
Pharmacokinetics of Geniposide by Monoclonal Antibody-Based icELISA in Mice after Oral Administration of Huanglian-Jiedu-Tang
}

\author{
Hui-Hua Qu, ${ }^{a}$ Ye Sun, ${ }^{b}$ Ting-Ting Wu, ${ }^{b}$ Gui-Liang Zhang, ${ }^{b}$ Jin-Jun Cheng, ${ }^{c}$ Xue-Qian Wang, ${ }^{b}$ \\ Hui-Bin Feng, ${ }^{c}$ Yan Zhao, ${ }^{*, b}$ and Qing-Guo Wang*,b \\ ${ }^{a}$ Center of Scientific Experiment, Beijing University of Chinese Medicine; ${ }^{b}$ School of Basic Medical Sciences, Beijing \\ University of Chinese Medicine; and ${ }^{c}$ School of Basic Medical Sciences, Beijing University of Chinese Medicine; 11 \\ North Third Ring Road East, Chaoyang District, Beijing 100029, China. \\ Received May 1, 2014; accepted June 14, 2014
}

\begin{abstract}
Geniposide, Geniposide, the main active component in extracts of Gardenia jasminoides EluIs., is one of the main components of Huanglian-Jiedu-Tang (HJT). This study aimed to validate an indirect competitive enzyme-linked immunosorbent assay (icELISA) based on monoclonal antibodies (mAb) against geniposide (anti-geniposide $\mathbf{m A b}$ ), which was developed by our lab, and apply the assay to study the pharmacokinetics of geniposide in HJT in mice. Blood samples were drawn from mice at predetermined time points after oral administration of $\mathrm{HJT}$ in three dosages. A linear correlation was obtained for geniposide concentrations in the range from 1.17 to $37.50 \mu \mathrm{g} / \mathrm{mL}$. The intra-day and inter-day precision values of the icELISA method were well within the recommended range $(\leq 10 \%)$. The recovery rates ranged from 99.74 to $102.40 \%$. Stability studies showed that geniposide sample solutions were intact for $12 \mathrm{~h}$. The $T_{\max }$ and mean residence time (MRT) of geniposide of the three groups were consistent with previous data. The results suggest that a reliable and effective method was established and could be applied to the study of the pharmacokinetics of geniposide in HJT.
\end{abstract}

Key words geniposide; monoclonal antibody; pharmacokinetics; indirect competitive enzyme-linked immunosorbent assay; Huanglian-Jiedu-Tang; mouse

Hanglian-Jiedu-Tang (HJT) is a famous traditional Chinese medicine (TCM) compound first described during the Tang Dynasty (Wai-Tai-Mi-Yao). HJT is composed of 4 Chinese herbs: Rhizoma Coptidis (Coptis chinensis Franch.), Radix Scutellariae (Scutellaria baicalensis Georgi.), Cortex phellodendri (Phellodendron amurense RuPReCht.) and Fructus Gardeniae (Gardenia jasminoides ElLIs.). ${ }^{1)}$ In modern medicine, HJT is used to treat cardiovascular and cerebrovascular diseases, such as cerebral ischemia. ${ }^{2}$ Numerous recent studies have described several pharmacological characteristics of HJT, including antioxidant, ${ }^{3-5)}$ anti-inflammatory, ${ }^{6,7)}$ and neuroprotective activities. ${ }^{8,9)}$ Geniposide, an iridoid glycoside, is the major medical component of the Fructus Gardeniae ${ }^{10)}$ (Fig. 1). Geniposide can cross the blood-brain barrier, ${ }^{11-13)}$ which makes it a promising therapeutics for brain diseases. Geniposide can inhibit damage due to ischemia and limit memory impairment through its antioxidant ${ }^{14}$ and antiinflammatory ${ }^{15,16)}$ activities. Therefore, geniposide is also one of the main components of HJT.

Despite of the efficacy in indications has been proved by clinic; there are still adverse effect reports of geniposide. ${ }^{17)}$ Therefore, the effective measures for trace detecting are needed in the pharmacology studies of geniposide.

Monoclonal antibodies $(\mathrm{mAb})$ are immunoglobulins with high specificity and biological activity, ${ }^{18}$ which have been extensively applied in prevention, diagnosis and treatment of diseases, detection of residues of pesticides and chloramphenicol in food samples, ${ }^{19)}$ and veterinary medicine development. The indirect competitive ELISA (icELISA), an immunological assay based on $\mathrm{mAb}$, was reported to provide a valuable tool for paclitaxel determination. ${ }^{20}$ In addition, icELISA methods were developed for detection of okadaic acid and

The authors declare no conflict of interest. dinophytoxin-1 in seafood, ${ }^{21)}$ and diethylstilbestrol in biological samples. ${ }^{22)}$

Pharmacokinetic studies are very important in drug development. Currently, high-performance liquid chromatography (HPLC), ${ }^{23)}$ HPLC-mass spectrum (MS)/MS, ${ }^{24)}$ gas chromatography $(\mathrm{GC})^{25)}$ and $\mathrm{GC}-\mathrm{MS}^{26)}$ are the main methods employed in pharmacokinetics. However, these methods need relatively large amounts of sample, requiring at least $0.2 \mathrm{~mL} \mathrm{blood}^{27)}$ at each time point. This does not allow accurate concentrationtime profiling of mouse samples: enough blood could not be obtained from one mouse at short time intervals and dozens of mice would be used if several animals were sacrificed per data point. ${ }^{28)}$ Moreover, currently used methods listed above do not accurately measure drug kinetics in mice. Therefore, a technology with higher detection sensitivity would greatly help in pharmacokinetic studies in small animals. The icELISA method was newly developed for this purpose. ${ }^{29)}$ This assay is more sensitive and requires only small sample amounts for detection, with simple sample preparation suitable for simultaneous assessment of large size samples. ${ }^{30}$

Clinical experiments have proven TCM effective. However,<smiles>COC(=O)C1=CO[C@@H](O[C@@H]2O[C@H](CO)[C@@H](O)[C@H](O)[C@H]2O)[C@H]2C(CO)=CC[C@H]12</smiles>

Fig. 1. Chemical Structure of Geniposide 
development of compound Chinese medicine requires comprehensive pharmacokinetic research. Since small doses are administered to animals and Chinese medicine products are composed of many molecules, tedious pretreatment including cleanup and concentration steps are required. Therefore, pharmacokinetic studies on Chinese medicine products in small animals (e.g., mouse) are scarce.

We recently produced anti-geniposide $\mathrm{mAb}$ from mouse ascitic fluid and developed an icELISA method for geniposide detection in vivo. ${ }^{31)}$ In this study, this method was applied for assessment of biological samples from mice and pharmacokinetics of geniposide in mice after oral administration of HJT in three dosages.

\section{MATERIALS AND METHODS}

Development of icELISA for Geniposide Determination. Synthesis and Identification of Artificial Geniposide Antigen We have previously synthesized artificial geniposide antigen by a sodium periodate oxidation method ${ }^{31)}$ using geniposide (98\%, HPLC, Batch number: 110752-200912, NIFDC, Beijing, China) with Bovine serum albumin (BSA) and poly-lysine (PLL) (Sigma-Aldrich Corporate Co. LLC, St. Louis, MO, U.S.A.). Geniposide-carrier protein conjugates were determined by thin layer chromatography (TLC), ultraviolet visible spectrophotometry (UV) as previously reported. $^{32,33)}$

Immunization was then initiated by subcutaneous injection of the synthesized immunogen. Mice were injected with $50 \mu \mathrm{L}$ geniposide-BSA conjugate $(1 \mathrm{mg} / \mathrm{mL})$ emulsified with the same volume of Freund's complete adjuvant (Sigma-Aldrich) at the first time, then injected with $50 \mu \mathrm{L}$ geniposide-BSA conjugate emulsified with the same volume of Freund's incomplete adjuvant (Sigma-Aldrich) at 2nd, 4th and 6th weeks after initiation. Blood samples were obtained from the tail vein after the fourth immunization, and the serum were isolated for the titer test by icELISA. ${ }^{31)}$

The icELISA procedures are as follows: Wells of flat-bottom 96-well microplates (NuncImmulon 4HBX; Fisher Scientific, Pittsburgh, PA, U.S.A.) were coated with $100 \mu \mathrm{L}$ of coating antigen (geniposide-PLL, $1 \mathrm{mg} / \mathrm{mL}$ ), diluted $1: 5000$ in carbonate buffer (20 mm $\mathrm{Na}_{2} \mathrm{CO}_{3}$ and $\left.40 \mathrm{~mm} \mathrm{NaHCO}_{3}, \mathrm{pH} 9.6\right)$. Plates were covered with sealing film, and incubated for $2 \mathrm{~h}$ at $37^{\circ} \mathrm{C}$, then washed 4 times on an orbital shaker with gentle agitation for $1 \mathrm{~min}$ with $300 \mu \mathrm{L}$ per well of Wash Buffer, comprised of $0.05 \% \mathrm{v} / \mathrm{v}$ Tween-20 (Sigma-Aldrich, Shanghai, China) in phosphate-buffered saline (PBS; Sigma-Aldrich) containing $11.9 \mathrm{~mm}$ phosphate, $137 \mathrm{~mm} \mathrm{NaCl}$, and $2.7 \mathrm{~mm} \mathrm{KCl}$, $\mathrm{pH}$ 7.4. Blocking Buffer $(200 \mu \mathrm{L})$ comprised of $10 \%$ horse serum (Oxoid, Basingstoke, U.K.) was added to each well, and plates were sealed and blocked for $2 \mathrm{~h}$ at $37^{\circ} \mathrm{C} .50 .00 \mu \mathrm{L}$ various concentrations of geniposide were added to each well, followed by an equal volume of the blood samples diluted with PBS. After incubation for $1 \mathrm{~h}$ at $37^{\circ} \mathrm{C}$, the plate was washed 4 times with Wash Buffer. Then, $100 \mu \mathrm{L}$ of goat anti-mouse secondary antibody conjugated to horse radish peroxidase (Goat Anti-Mouse IgG, R\&D Systems, Minneapolis, MN, U.S.A.) was diluted 1:10000 in PBS, then added to each well. After plates were sealed and incubated for $0.5 \mathrm{~h}$ at $37^{\circ} \mathrm{C}$, the wells were washed and $100 \mu \mathrm{L}$ of the 3,3',5,5'-tetramethylbenzidine (TMB) substrate (Sigma-Aldrich) were added. The plates were sealed, protected from light and incubated at $37^{\circ} \mathrm{C}$. The reaction was stopped after $15 \mathrm{~min}$ by adding $50 \mu \mathrm{L}$ of Stop Solution $\left(2.00 \mathrm{~mol} / \mathrm{mL} \mathrm{H}_{2} \mathrm{SO}_{4}\right)$. The plate was read at $450 \mathrm{~nm}$ with a microplate reader (ELx800, BioTek, Winooski, VT, U.S.A.). Blank blood and PBS were used as the negative control and blank, respectively.

Cell Fusion and Preparation of Anti-geniposide mAb Male BALB/c mice (7 weeks old) were purchased from Vital River Laboratories (Beijing, China). Food (Keaoxieli Animal Feed Co., Ltd., Beijing, China) and water which can be freely accessed were sufficiently provided twice a week. All animal life care and experimental procedures were conducted according to the Guidelines for Animal Experiments of the School of Basic Medical Sciences and were approved by the Committee on Ethics of Animal Experiments, using the code 2013BZHYLL00106, Beijing University of Chinese Medicine, China.

Cell fusion was conducted on the third day after the final immunization, according to the method using polyethylene glycol $(\mathrm{PEG})^{34,35)}$ (Sigma-Aldrich). Splenocytes were isolated and fused with the hypoxanthine-aminopterin-thymidine (HAT) (Sigma-Aldrich) sensitive mouse myeloma cell line, SP2/0, which was obtained from Sciencell Research Laboratory (Carlsbad, CA, U.S.A.). The hybridoma cells were transferred to 96-well plates (Corning, NY, U.S.A.) for cell culture. Cells producing $\mathrm{mAb}$ reactive to geniposide were identified by indirect ELISA and were cloned by the limiting dilution method. ${ }^{36,37)}$ The established hybridoma was cultured in HT medium (Sigma-Aldrich).

Specificity of icELISA Antibody specificity was evaluated by determining cross-reactivity (CR) with geniposide analogs known to compete with the binding of the antibody to the coating antigen in icELISA following the procedure above. The $\mathrm{CR}$ was determined by comparing the $\mathrm{IC}_{50}$ of the competitors with that of geniposide, and calculated according to Weiler's equation. ${ }^{38)}$

Correlations between icELISA and HPLC for the Determination of Geniposide Sample Preparation Geniposide was dried to constant weight and accurately weighed before being dissolved in methanol (Sinopharm Chemical Reagents Beijing Co., Ltd., China). The solution was ultrasonicated for $30 \mathrm{~min}$, cooled to room temperature, and then further diluted in methanol prior to filtration $(0.45 \mu \mathrm{m}$ microporous membrane) (Jinteng Experimental Equipment Co., Ltd., Tianjin, China).

Chromatographic Conditions The Agilent 1260 series liquid chromatograph (Agilent Technologies, Palo Alto, CA, U.S.A.), is equipped with a quaternary pump, an autosampler and a thermostatically controlled column apartment. Geniposide was separated using an Agilent ZORBAX SB-C18 column $(4.6 \times 250 \mathrm{~mm}, 5 \mu \mathrm{m})$ protected by a $\mathrm{C} 18$ guard column (Agilent Technologies). The mobile phase for HPLC analysis consisted of a mixture of acetonitrile and water $(25: 75, \mathrm{v} / \mathrm{v})$. The analysis was carried out at a flow rate of $1.00 \mathrm{~mL} / \mathrm{min}$ for an isocratic elution. The column temperature was maintained at $25^{\circ} \mathrm{C}$ and the detection wavelength was set at $238 \mathrm{~nm}$. The sample injection volume was $10.00 \mu \mathrm{L}$.

Correlation Studies in Chinese Herbal Compounds Determination of geniposide concentrations in variety of Chinese herbal compounds (Baipi Decoction, Bai Gui Decoction, Shen Zhu Decoction, Fu Zhi Jian, Cangzu San, Huanglian 
Banxia Decoction, Chai Qin Liang Jie decoction, BanXia Jie Du Decoction, HuangLian Jie Du Decoction and Zhizi Baipi Decoction) were compared using HPLC and icELISA methods in parallel.

Herbal Preparation of HJT HJT granules (China Resources Sanjiu Medical \& Pharmaceutical Co., Ltd.) containing 4 components, Radix Scutellariae (1210003S, $1 \mathrm{~g}$ is equivalent to $3 \mathrm{~g}$ crude drug), Rhizoma Coptidis (1111001S, $1.5 \mathrm{~g}$ is equivalent to $10 \mathrm{~g}$ crude drug), Cortex Phellodendri (1211001S, $0.5 \mathrm{~g}$ is equivalent to $6 \mathrm{~g}$ crude drug), and Fructus Gardeniae (1206001S, $1 \mathrm{~g}$ is equivalent to $3 \mathrm{~g}$ crude drug), were mixed and dissolved in $40 \mathrm{~mL}$ boiling purified water and stored at $4^{\circ} \mathrm{C}$. The middle dose consisted of $1.5 \mathrm{~g}$ Radix Scutellariae, $0.45 \mathrm{~g}$ Rhizoma Coptidis, $0.25 \mathrm{~g}$ Cortex Phellodendri and $0.45 \mathrm{~g}$ Fructus Gardeniae. The low dose contained half of middle dose; the high dose was twice of middle dose. To determine appropriate doses, the standard human clinical dose ( $12 \mathrm{~g} / \mathrm{d}$ for a $60-\mathrm{kg}$ adult) was converted to a dosage for mice, according to dose translation protocols 31 ) and body surface area normalization methods. HJT solutions were administered by oral gavage to mice.

Quantification of Geniposide in HJT The icELISA assays were used to quantify geniposide levels. All reagents were equilibrated to room temperature for $30 \mathrm{~min}$. The coating and blocking procedures followed above in the part of Development of icELISA for geniposide determination. During this time, the samples and standards were prepared. Aliquots of HJT solution $(50 \mu \mathrm{L})$, diluted 10 -fold in PBS buffer, and standards of geniposide $(50 \mu \mathrm{L})$ were added to wells of the precoated microtiter plate. Then, $50 \mu \mathrm{L}$ of anti-geniposide $\mathrm{mAb}$ $(1.2 \mathrm{mg} / \mathrm{mL})$ were added to each well and mixed. PBS buffer without $\mathrm{mAb}$ was used as a control. The plate was covered and incubated for $1 \mathrm{~h}$ at $37^{\circ} \mathrm{C}$. The following steps were the same as described above.

Finally, a linear standard curve was generated using 3 sets of duplicate, serially diluted standards. Sample concentrations were interpolated according to the standard curve.

Animals and Drug Administration All animal protocols were reviewed and approved by the Institutional Animal Care and Use Committee of the Beijing University of Chinese Medicine with the IRB code 2013BZHYLL00106. All animal experiments adhered to the guidelines and procedures for the care of laboratory animals. Animals were housed in a 12-h light-dark cycle at 20 to $26^{\circ} \mathrm{C}$ and had free access to food and water. Animals were fasted for $12 \mathrm{~h}$ with free access to water before treatment. Twenty-four male Kunming mice ( $30 \pm$ $4 \mathrm{~g}$ ) were chosen randomly and assigned to the experimental groups. Three doses of HJT prepared above were administrated to mice by gavage. Access to water was restricted for $24 \mathrm{~h}$ after treatment, and then supplied freely.

Blood Collection Blood samples $(0.01 \mathrm{~mL})$ were collected into heparinized quantitative capillary glass tubes from mouse tails and diluted 10 times with PBS. Blood samples were collected prior to drug administration and at 5, 15, 30, 45, 60, $90,120,150,180,210,240,360,480,600$ and $720 \mathrm{~min}$ after drug exposure. Samples were stored at $4^{\circ} \mathrm{C}$ for $24 \mathrm{~h}$ prior to analyses.

Development and Validation of Quantification Methods for Plasma The icELISA assay procedures were performed as described above, except that mice plasma was tested. The standards and the blank control were prepared in control mouse plasma. To determine inter-well precision, as well as intra-day variability, 3 standard solutions with different concentrations were selected, and 4 replicates were added to the pretreated plate and quantified, then the same experiment was repeated 6 times per day. To evaluate inter-day assay variability, the experiment was performed on multiple days, each time with 4 replicates. The coefficient of variation (CV), defined as $\mathrm{CV}=$ (standard deviation (S.D.) $/$ mean $) \times 100$, was determined. The recommended CV for immunoassays is $\leq 10 \%$.

To determine the efficiency of geniposide recovery, mouse plasma was spiked with purified geniposide at 5, 15 and $30 \mu \mathrm{g} /$ $\mathrm{mL}$. Recovery was calculated using geniposide concentration values and the equation: (observed concentration)/(spiked concentration $) \times 100$. S.D. were obtained from 8 sets of duplicate values.

To determine the sensitivity of the assay, 11 concentrations of geniposide were prepared by serial dilution from 300 to $0.293 \mu \mathrm{g} / \mathrm{mL}$. Samples were measured in 3 sets of duplicate values, and 24 replicates of blank samples were measured. The linear range was calculated by a competitive inhibition curve. The limit of detection (LOD) was determined as (blank value \pm 3 S.D.), where S.D. is the S.D. of the blank value. The limit of quantification (LOQ) was the floor of the linear calibration range.

To measure stability, 3 concentrations of geniposide were: 1) kept at room temperature for $12 \mathrm{~h}$ (short-term stability), 2) stored at $-20^{\circ} \mathrm{C}$ for $30 \mathrm{~d}$ (long-term stability), or 3) stored at $-20^{\circ} \mathrm{C}$ with 3 freeze-thaw cycles and then moved to room temperature.

Data Analyses The pharmacokinetic parameters were calculated using the non-compartment model and the Kinetica 4.4 software (Thermo Scientific, U.S.A.). The area under the serum concentration-time curve $\left(A U C_{0-t}\right)$ to the last point, the peak plasma concentration $\left(C_{\max }\right)$, the time to peak concentration $\left(T_{\max }\right)$, and the mean residence time (MRT) were obtained. The ANOVA was used for statistical analyses.

\section{RESULTS}

Production of Anti-geniposide mAb The artificial geniposide antigen was successfully generated and determined by TLC and UV as described previously. The hyper-immunized $\mathrm{BALB} / \mathrm{c}$ mice used to derive the cell clones described in this paper yielded splenocytes that were fused with SP2/0 myeloma cells by the general fusion protocols using PEG method. Hybridoma producing $\mathrm{mAb}$ reactive to geniposide were obtained. Ascites induced by transplant of this hybridoma into abdominal cavity of BALB/c mice was centrifuged and filtered (anti-geniposide $\mathrm{mAb}$ ). These ascites were then stored at $-20^{\circ} \mathrm{C}$ until further analysis.

Assay Sensitivity and Specificity The polystyrene immunoplate was coated with $1.00 \mu \mathrm{g} / \mathrm{mL}$ geniposide-PLL coating antigen, and the optimal concentration of anti-geniposide $\mathrm{mAb}$ was screened by indirect ELISA. The minimum concentration of $\mathrm{mAb}$ required to give measureable detection was $10.00 \mathrm{ng} /$ $\mathrm{mL}$. The icELISA was established using $1.00 \mu \mathrm{g} / \mathrm{mL}$ coating antigen and a $10.00 \mathrm{ng} / \mathrm{mL}$ anti-geniposide $\mathrm{mAb}$. A calibration curve of inhibition was generated using various amounts of geniposide to compete with the coating antigen. Under these conditions, a linear range for geniposide determination was $1.17-37.50 \mu \mathrm{g} / \mathrm{mL}$ with a detection limit of $256.00 \mathrm{ng} / \mathrm{mL}$ was 


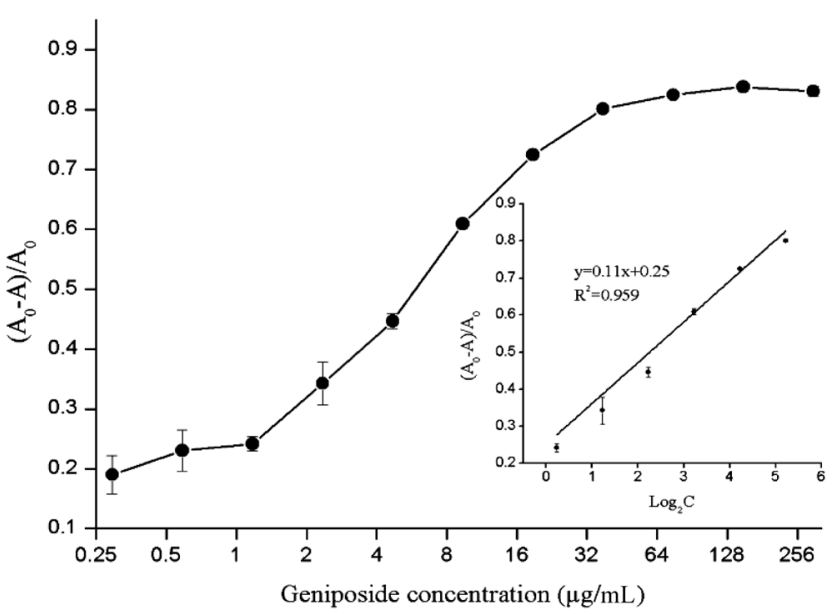

Fig. 2. Linear Calibration Curve of Inhibition by Geniposide Using $\mathrm{mAb}$ in an Indirect Competitive ELISA

$A_{0}$ is the absorbance with no geniposide present; and $A$ is the absorbance with geniposide present

revealed (Fig. 2).

The specificity of an immunoassay reflects the extent of cross-reactivity of the antibody used in the assay. As shown in Table 1, anti-geniposide $\mathrm{mAb}$ were highly specific, with less than $0.05 \% \mathrm{CR}$ against geniposidic acid (iridoid) and only $1.15 \%$ CR against saikosaponin A (triterpenoid saponin) and $1.03 \% \mathrm{CR}$ against puerarin (isoflavonoid). No CR against any of the other related compounds was detected, such as baicalin (flavonoid), paeoniflorin (monoterpene), chlorogenic acid (phenol), and so on.

Comparison between HPLC and icELISA for the Determination of Geniposide Assay Validation of HPLC Method A series of standard solution of concentration $81.00 \mu \mathrm{g} / \mathrm{mL}, 40.50 \mu \mathrm{g} / \mathrm{mL}, 20.25 \mu \mathrm{g} / \mathrm{mL}, 10.13 \mu \mathrm{g} / \mathrm{mL}, 5.06 \mu \mathrm{g} /$ $\mathrm{mL}$ and $2.53 \mu \mathrm{g} / \mathrm{mL}$ were prepared and detected by HPLC. A linear regression analysis of the calibration data was performed using the equation $y=14.505 x+1.11, R^{2}=1$, where $y$ is the peak area of geniposide, $x$ is the concentration. The linear range is $2.53-81.00 \mu \mathrm{g} / \mathrm{mL}$. The lower limit of quantification (LLOQ) of geniposide was found to be $2.53 \mu \mathrm{g} / \mathrm{mL}$. Precision and accuracy for the analysis of geniposide using HPLC is satisfactory $(\mathrm{RSD}<15 \%)$. Mean recovery in the range of $80 \%$ to $120 \%$ was obtained. The high stability of geniposide suggests that samples were not affected during preparation and analytical processing.

Comparison between icELISA and HPLC for the Determination of Geniposide The results for the determination of geniposide in a variety of Chinese herbal compounds using icELISA and HPLC are shown in Table 2. It indicates that there was a good correlation between icELISA and HPLC method $\left(R^{2}=0.9987\right)$, and that icELISA method can be used for determination of geniposide.

Geniposide Measurements The average (mean \pm S.D.) concentration of geniposide in the HJT solutions were shown in Fig. 3. Precision measurements were performed to quantify the geniposide in serum. The intra-day and inter-day precision values were well within the recommended range (Table 3). To demonstrate that geniposide was efficiently measured in plasma, plasma samples were spiked with defined concentrations of geniposide, and the recoveries were determined. The recoveries of geniposide at spike concentrations of 5, 15 and
$30 \mu \mathrm{g} / \mathrm{mL}$ from plasma were $103.38 \% \pm 2.06 \%, 97.60 \% \pm 3.89 \%$ and $96.38 \% \pm 5.89 \%$, respectively (Table 4). The sensitivity of geniposide measurements was also determined. Competitive inhibition and linear calibration curves were plotted with inhibition rates $\left[\left(A_{0}-A\right) / A_{0}\right]$ on the $y$-axes and geniposide concentrations on the $x$-axes. The linear calibration curves and regression equations were used to determine the geniposide concentrations. The full linear curve ranged from 1.17 to $37.5 \mu \mathrm{g} / \mathrm{mL}$, LOD ranged from 0.14 to $0.45 \mu \mathrm{g} / \mathrm{mL}$, and the LOQ was $1.17 \mu \mathrm{g} / \mathrm{mL}$ (Fig. 3). Sample stability is an important practical consideration for all biological specimens. Our results suggested that the geniposide concentrations were reduced after geniposide was stored at $-20^{\circ} \mathrm{C}$ for $30 \mathrm{~d}$ and subjected to 3 freeze-thaw cycles. Therefore, to prevent loss, small volumes of solutions containing geniposide should be frozen and not subjected to freeze-thaw cycles (Table 5). The specificity of the anti-geniposide antibody was determined by using the cross-reactivity measurements described by Weiler and Zenk. ${ }^{38)}$

Pharmacokinetic Parameters of Geniposide Figure 3 depicts the serum concentration profiles of geniposide in mice after oral administration of HJT solutions. Based on this assay, the $C_{\max }, T_{\max }, A U C_{0-t}$ and MRT were calculated. The pharmacokinetic parameters are listed in Table 6 . The differences on $C_{\max }$ and $A U C_{0-t}$ may be caused by the different dosages, we compared $A U C_{0-t}$ of geniposide with the dose of HJT and found there was a linearity (Fig. $4, R^{2}=0.9354$ ).

\section{DISCUSSION}

The most frequently used methods for geniposide detection are based on chromatography and mass spectrometry techniques. ${ }^{7,39,40)}$ Though these methods are sensitive and specific, because of the complexity of pharmacokinetic studies on Chinese medicine compounds, the disadvantages of these methods have been revealed. Firstly, cleanup and pre-concentration steps consisting of liquid-liquid extraction followed by solid-phase extraction procedures are required, rendering high sample volume and very difficult to screen large numbers of samples in a timely way. Because limited quantities of blood can be drawn from small animals, experiments requiring many time points cannot be collected from the same animal with this method. Indeed, at least three mice are usually sacrificed at each time point to get adequate sample and meet statistical requirements. ${ }^{41)}$ As a result, plenty of mice must be sacrificed to acquire a complete concentration-time profile in pharmacokinetics studies. Still, concentration versus time curves generated by samples from different animals may not accurately represent in vivo drug absorption. Moreover, some studies have used rats, anesthetized throughout the experimental period ${ }^{42}$ when blood samples were collected via the vena orbitalis, a procedure that affects drug bioavailability. Therefore, to address the need of pharmacokinetic studies on Chinese medicine compounds, detection methods with high sensitivity and high-throughput are needed.

To overcome the problems associated with determining the pharmacokinetics of geniposide, we developed a novel icELISA methods based on anti-geniposide $\mathrm{mAb}$ to quantify geniposide. Our method that required small sample sizes was sensitive and efficient. In this study, blood samples of $10 \mu \mathrm{L}$ were more than enough at each time point for detection, 
Table 1. Cross-Reactivity of Anti-geniposide mAb against Related Compounds

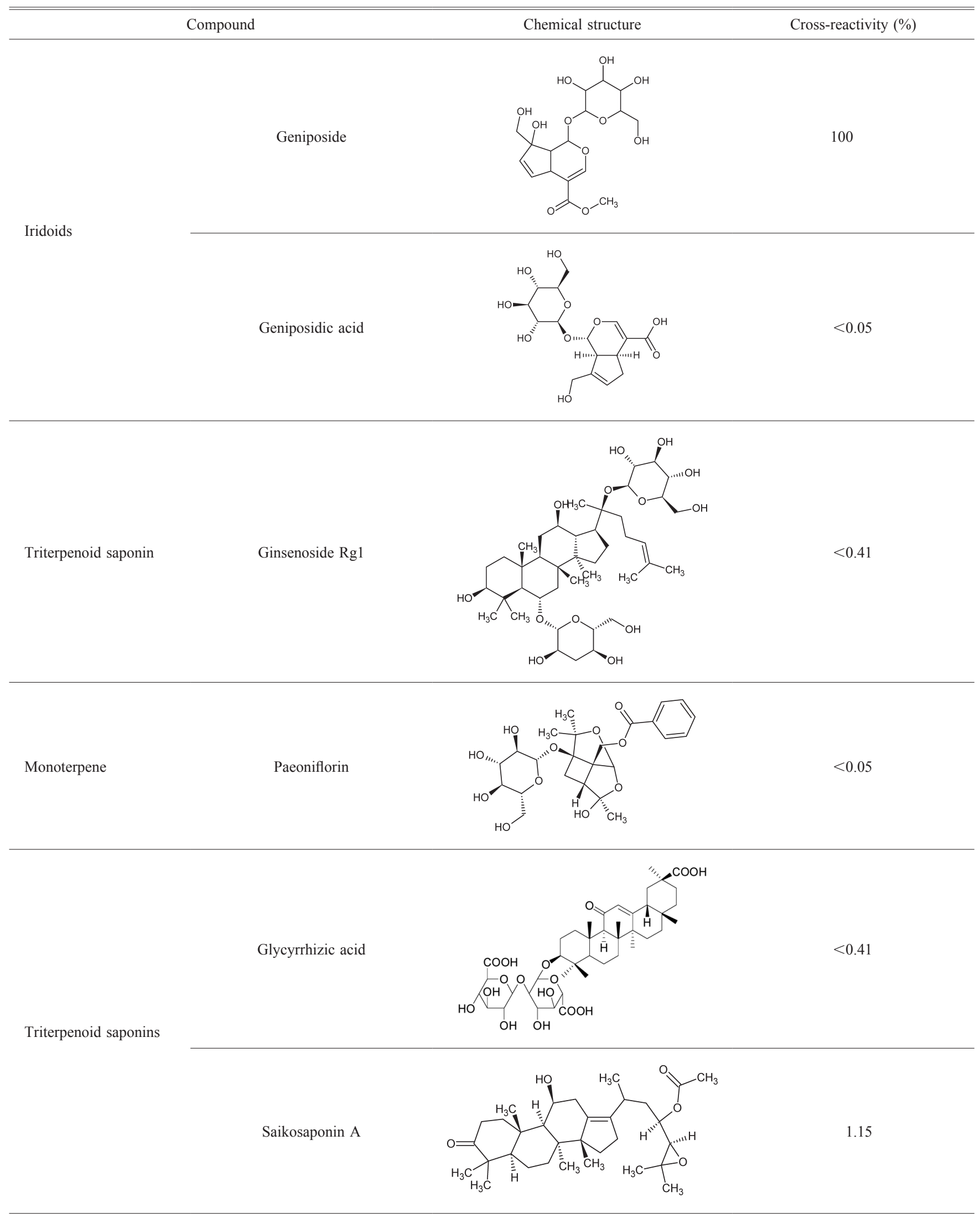


Table 1. Continued.

Compound Cross-reactivity (\%)

Cross-reactivity (\%) was determined according to Weiler's equation.

Table 2. Comparison between icELISA and HPLC for the Determination of Geniposide in Chinese Herbal Compounds (Mean \pm S.D.)

\begin{tabular}{|c|c|c|c|}
\hline \multirow{2}{*}{ Chinese herbal compounds } & \multirow{2}{*}{ Components } & \multicolumn{2}{|c|}{ Measured concentration $(\mu \mathrm{g} / \mathrm{mL})$} \\
\hline & & icELISA & HPLC \\
\hline Baipi Decoction & Baipi, Huanglian, Zhizi, Ejiao & $13.05 \pm 0.31$ & $12.78 \pm 0.35$ \\
\hline Bai Gui Decoction & $\begin{array}{l}\text { Fuling, Gancao, Zhizi, Huangbai, } \\
\text { Rougui }\end{array}$ & $9.25 \pm 0.21$ & $9.10 \pm 0.27$ \\
\hline Shen Zhu Decoction & $\begin{array}{l}\text { Huangbai, Danggui, Chaihu, } \\
\text { Shengma, Renshen, Chenpi, } \\
\text { Qingpi,Shengqu, Gancao, Cangzhu, } \\
\text { Huangqi }\end{array}$ & $9.42 \pm 0.19$ & $9.38 \pm 0.30$ \\
\hline Fu Zhi Jian & Zhizi, Xiangfu, Chuangxiong & $18.25 \pm 0.32$ & $17.57 \pm 0.64$ \\
\hline Cangzu San & Zhizi, Fuzi & $15.85 \pm 0.28$ & $15.63 \pm 0.36$ \\
\hline Huanglian Banxia Decoction & Huanglian, Banxia, Zhizi & $14.06 \pm 0.31$ & $13.79 \pm 0.43$ \\
\hline Chai Qin Liang Decoction & Chaihu, Huangqin, Zhizi & $8.74 \pm 0.13$ & $8.48 \pm 0.19$ \\
\hline BanXia Jie Du Decoction & Huangbai, Huangqin, Zhizi, Banxia & $11.65 \pm 0.36$ & $11.06 \pm 0.77$ \\
\hline Huanglian Jie Du Decoction & $\begin{array}{l}\text { Huanglian, Huangbai, Huangqin, } \\
\text { Zhizi }\end{array}$ & $24.66 \pm 0.92$ & $24.57 \pm 1.04$ \\
\hline Zhizi Baipi Decoction & Zhizi, Gancao, Huangbai & $26.03 \pm 1.03$ & $25.64 \pm 0.92$ \\
\hline
\end{tabular}

allowing us to monitor drug metabolism over a long timecourse in the same animal. Correspondingly, the method was sufficiently sensitive to detect trace amounts of geniposide $12 \mathrm{~h}$ after administration. Although the assay range of the icELISA method we established shows on $\mu \mathrm{g} / \mathrm{mL}$ level, it can be used to detect in samples with volume of microliter scale, which won't be achieved by HPLC, LC-MS, GC-MS analysis method and is important for the pharmacokinetics researches. In our experiments, mice are in a non-anesthetized state for blood sample collection (via tail vein). Indeed, small sample volumes and sample collection site are very beneficial not only for pharmacokinetic studies in small animals, but also for minimizing animals' sacrifices. Furthermore, simplified protocols that may be conducted routinely in the laboratory allow us to process many samples in a timely way. These advantages enabled us to present long-term, accurate pharmacokinetic parameters of Chinese medicine compounds.

Although pharmacokinetics and assessment of geniposide in blood samples have been widely reported, ${ }^{43,44)}$ there is no pharmacokinetic study using icELISA in mice. Results from the icELISA experiments indicated the method was accurate, specific, sensitive, and reproducible. The measured value of geniposide in serum indicated that the $T_{\max }$ and MRT of geniposide of HJT in mice were consistent with previous data. ${ }^{14)}$ The different pharmacokinetic parameters of geniposide between three groups indicated that the pharmacokinetics of geniposide of HJT were different in mice and the variation of geniposide $A U C_{0-t}$ were dose dependent with HJT. It confirmed that geniposide pharmacokinetic study provides a theoretical basis for clinical rational compatibility of Fructus 


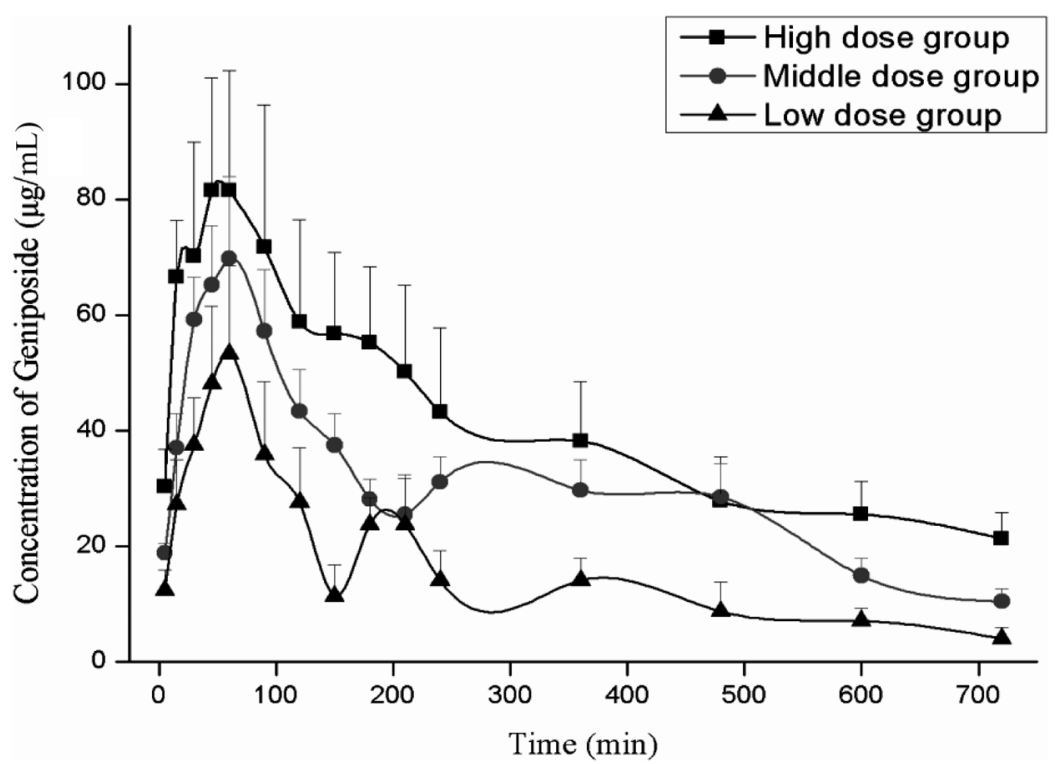

Fig. 3. Comparison of Mean Geniposide Concentration-Time Curves in Blood Samples from Mice Following Oral Administration of Three Dose Groups

Table 3. Intra-day and Inter-day Precisions of Geniposide in the Plasma of Mice (Mean \pm S.D.)

\begin{tabular}{|c|c|c|c|c|c|}
\hline \multirow[b]{2}{*}{ Sample } & \multirow{2}{*}{$\begin{array}{l}\text { Theoretical concentration } \\
\qquad(\mu \mathrm{g} / \mathrm{mL})\end{array}$} & \multicolumn{2}{|c|}{ Intra-day } & \multicolumn{2}{|c|}{ Inter-day } \\
\hline & & $\begin{array}{l}\text { Measured concentration } \\
\qquad(\mu \mathrm{g} / \mathrm{mL})\end{array}$ & $\begin{array}{c}\text { Precision CV } \\
(\%)\end{array}$ & $\begin{array}{l}\text { Measured concentration } \\
\qquad(\mu \mathrm{g} / \mathrm{mL})\end{array}$ & $\begin{array}{c}\text { Precision CV } \\
(\%)\end{array}$ \\
\hline 1 & 30 & $30.73 \pm 1.22$ & 3.97 & $30.77 \pm 1.41$ & 4.59 \\
\hline 2 & 15 & $15.14 \pm 0.62$ & 4.13 & $15.29 \pm 0.76$ & 4.95 \\
\hline 3 & 5 & $5.22 \pm 0.22$ & 4.25 & $5.17 \pm 0.27$ & 5.25 \\
\hline
\end{tabular}

Table 4. Spike Recovery of Geniposide in Mice Plasma (Mean \pm S.D.)

\begin{tabular}{cccr}
\hline \hline Sample & Nominal concentration $(\mu \mathrm{g} / \mathrm{mL})$ & Measured concentration $(\mu \mathrm{g} / \mathrm{mL})$ & Recovery $(\%)$ \\
\hline 1 & 30 & $30.39 \pm 0.92$ & $101.30 \pm 3.05$ \\
2 & 15 & $14.96 \pm 0.78$ & $99.74 \pm 5.22$ \\
3 & 5 & $5.12 \pm 0.23$ & $102.40 \pm 4.64$ \\
\hline
\end{tabular}

Table 5. Stability of Geniposide in Mice Plasma (Mean \pm S.D.)

\begin{tabular}{|c|c|c|c|c|c|c|}
\hline \multirow[b]{2}{*}{ Sample } & \multicolumn{2}{|c|}{$12 \mathrm{~h}$ at room temperature } & \multicolumn{2}{|c|}{3 Freeze/Thaw cycles } & \multicolumn{2}{|c|}{$30 \mathrm{~d}$ at $-20^{\circ} \mathrm{C}$} \\
\hline & $\begin{array}{c}\text { Measured concentration } \\
(\mu \mathrm{g} / \mathrm{mL})\end{array}$ & $\begin{array}{c}\text { Precision } \mathrm{CV} \\
(\%)\end{array}$ & $\begin{array}{c}\text { Measured concentration } \\
(\mu \mathrm{g} / \mathrm{mL})\end{array}$ & $\begin{array}{c}\text { Precision CV } \\
(\%)\end{array}$ & $\begin{array}{c}\text { Measured concentration } \\
\qquad(\mu \mathrm{g} / \mathrm{mL})\end{array}$ & $\begin{array}{c}\text { Precision CV } \\
(\%)\end{array}$ \\
\hline 1 & $30.14 \pm 1.10$ & 3.65 & $28.89 \pm 1.26$ & 4.37 & $28.69 \pm 0.56$ & 1.94 \\
\hline 2 & $14.79 \pm 0.57$ & 3.88 & $14.14 \pm 0.68$ & 4.85 & $14.46 \pm 0.58$ & 4.04 \\
\hline 3 & $5.28 \pm 0.16$ & 3.10 & $4.67 \pm 0.27$ & 5.79 & $4.83 \pm 0.27$ & 5.63 \\
\hline
\end{tabular}

Table 6. Pharmacokinetic Parameters of Geniposide after Oral Administration of Different Dosages of HJT in Mice (Mean \pm S.D., $n=8$ )

\begin{tabular}{lccc}
\hline \hline Group & High dose group & Middle dose group & Low dose group \\
\hline$C_{\max }(\mu \mathrm{g} / \mathrm{mL})$ & $85.46 \pm 21.05$ & $69.79 \pm 14.12$ & $53.31 \pm 15.18$ \\
$T_{\max }(\mathrm{min})$ & $58.13 \pm 14.87$ & $60.00 \pm 0.00$ & $58.13 \pm 5.30$ \\
$A U C_{0-t}(\mu \mathrm{g} / \mathrm{mL} \cdot \mathrm{min})$ & $29373.14 \pm 7738.65$ & $21406.83 \pm 3708.76$ & $11352.93 \pm 3742.17$ \\
$A U C_{\text {tot }}$ & $44171.38 \pm 11978.81$ & $24009.26 \pm 4147.89$ & $12650.82 \pm 4475.33$ \\
MRT $(\min )$ & $662.37 \pm 145.04$ & $354.00 \pm 13.26$ & $311.60 \pm 32.86$ \\
\hline
\end{tabular}




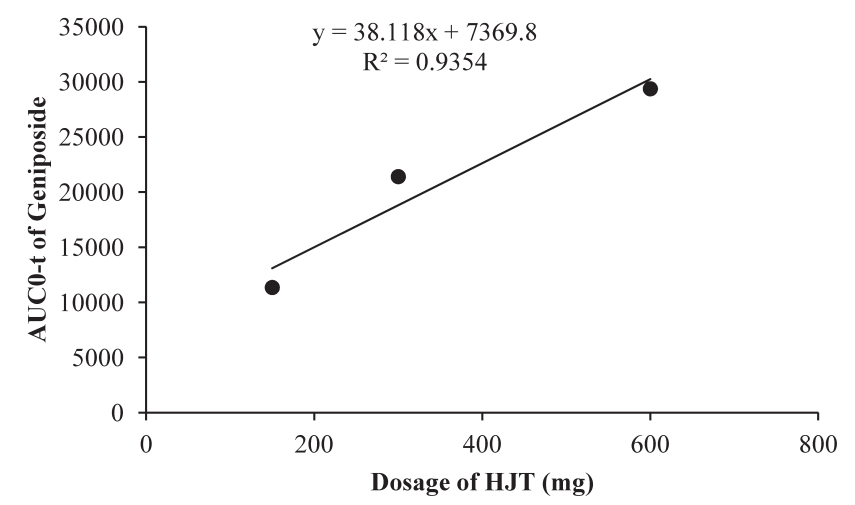

Fig. 4. Correlation between Oral Dosage of HJT and $A U C_{0-t}$ of Geniposide

\section{Gardeniae in TCM.}

The icELISA method we used has good prospect in testing the trace content of geniposide, It can not only be used in the geniposide detection in Fructus Gardeniae and related Chinese Medicine for quality control and drug development, but also in the residue detection for possible adverse effect researches of geniposide.

\section{CONCLUSION}

The icELISA using anti-geniposide mAb developed in this study are accurate, specific, sensitive, and reproducible. A reliable and effective method was established to be applied to the pharmacokinetics of geniposide derived from HJT.

Acknowledgments This work was supported by the National Natural Science Foundation of China (81274043, 81373542, 81373886), and the Science and Technology Major Projects for Major New Drugs (2012ZX09103201-007) and the Classical Prescription Basic Rresearch Team of Beijing University of Chinese Medicine.

\section{REFERENCES}

1) $\mathrm{Hu} \mathrm{Y}, \mathrm{Hu} \mathrm{Z}$, Wang $\mathrm{S}$, Dong $\mathrm{X}$, Xiao $\mathrm{C}$, Jiang $\mathrm{M}$, Lv A, Zhang W, Liu R. Protective effects of Huang-Lian-Jie-Du-Tang and its component group on collagen-induced arthritis in rats. $J$. Ethnopharmacol., 150, 1137-1144 (2013).

2) Hwang YS, Shin CY, Huh Y, Ryu JH. Hwangryun-Hae-Dok-Tang (Huanglian-Jie-Du-Tang) extract and its constituents reduce ischemiareperfusion brain injury and neutrophil infiltration in rats. Life Sci., 71, 2105-2117 (2002).

3) Sekiya N, Shibahara N, Sakakibara I, Hattori N, Goto H, Terasawa K. Inhibitory effects of Oren-Gedoku-To (Huanglian-Jie-Du-Tang) on free radical-induced lysis of human red blood cells. Phytother. Res., 17, 147-151 (2003).

4) Sekiya N, Kogure T, Kita T, Kasahara Y, Sakakibara I, Goto H, Shibahara N, Shimada Y, Terasawa K. Reduction of plasma triglyceride level and enhancement of plasma albumin concentration by Oren-gedoku-to administration. Phytomedicine, 9, 455-460 (2002).

5) Sekiya N, Kainuma M, Hikiami H, Nakagawa T, Kouta $K$, Shibahara N, Shimada Y, Terasawa K. Oren-gedoku-to and Keishibukuryo-gan-ryo inhibit the progression of atherosclerosis in diet-induced hypercholesterolemic rabbits. Biol. Pharm. Bull., 28, 294-298 (2005).

6) Yue R, Zhao L, Hu Y, Jiang P, Wang S, Xiang L, Liu W, Shan L, Zhang W, Liu R. Metabolomic study of collagen-induced arthritis in rats and the interventional effects of huang-lian-jie-du-tang, a traditional chinese medicine. Evid. Based Complement. Alternat. Med., 2013, 439690 (2013).

7) Zhu H, Qian Z, Li H, Guo L, Pan L, Zhang Q, Tang Y. Integrated pharmacokinetics of major bioactive components in MCAO rats after oral administration of Huang-Lian-Jie-Du-Tang. J. Ethnopharmacol., 141, 158-169 (2012).

8) Hu Y, Jiang P, Wang S, Yan S, Xiang L, Zhang W, Liu R. Plasma pharmacochemistry based approach to screening potential bioactive components in Huang-Lian-Jie-Du-Tang using high performance liquid chromatography coupled with mass spectrometric detection. J. Ethnopharmacol., 141, 728-735 (2012).

9) Zhang Q, Ye YL, Yan YX, Zhang WP, Chu LS, Wei EQ, Yu YP. Protective effects of Huanglian-Jiedu-Tang on chronic brain injury after focal cerebral ischemia in mice. Zhejiang Da Xue Xue Bao Yi Xue Ban, 38, 75-80 (2009).

10) Gao L, Zhu BY. The accumulation of crocin and geniposide and transcripts of phytoene synthase during maturation of Gardenia jasminoides fruit. Evid. Based Complement Alternat. Med., 2013, 686351 (2013).

11) Dong XP, Ruan M, Yu B, Jin L, Zhu DQ, Fang TH. Effects of borneol at different doses on concentration of geniposide in rat brains. Chin. Tradit. Herb. Drugs, 43, 1366-1370 (2012).

12) Gao YH, Wang YY, Xiao SY, Ye LY, Lou JN, Luo GA, Wang SR. Study of effective components of Qingkailing through an in vitro blood-brain barrier. J. Beijing Univ. Tradit. Chin. Med, 28, 26-28 (2005).

13) Chen ZZ, Lu Y, Du SY, Shang KX, Cai CB. Influence of borneol and muscone on geniposide transport through MDCK and MDCKMDR1 cells as blood-brain barrier in vitro model. Int. J. Pharm., 456, 73-79 (2013).

14) Zhou J, Qiu BH, Pan LM, Zhu HX, Guo LW. Study on pharmacokinetics- pharmacodynamics of geniposide in Huanglian-Jiedu-Tang active fraction (HLJDTAF). Chin. Hosp. Pharm. J., 32, 487-491 (2012).

15) Koo HJ, Lim KH, Jung HJ, Park EH. Anti-inflammatory evaluation of gardenia extract, geniposide and genipin. J. Ethnopharmacol., 103, 496-500 (2006)

16) Wang J, Hou J, Zhang P, Li D, Zhang C, Liu J. Geniposide reduces inflammatory responses of oxygen-glucose deprived rat microglial cells via inhibition of the TLR4 signaling pathway. Neurochem. Res., 37, 2235-2248 (2012).

17) Hiramatsu K, Sakata H, Horita Y, Orita N, Kida A, Mizukami A, Miyazawa M, Hirai S, Shimatani A, Matsuda K, Matsuda M, Ogino H, Fujinaga H, Terada I, Shimizu K, Uchiyama A, Ishizawa S, Abo H, Demachi H, Noda Y. Mesenteric phlebosclerosis associated with long-term oral intake of geniposide, an ingredient of herbal medicine. Aliment. Pharmacol. Ther., 36, 575-586 (2012).

18) Dirnhofer S, Klieber R, De Leeuw R, Bidart JM, Merz WE, Wick $\mathrm{G}$, Berger P. Functional and immunological relevance of the $\mathrm{COOH}-$ terminal extension of human chorionic gonadotropin beta: implications for the WHO birth control vaccine. FASEB J., 7, 1381-1385 (1993).

19) Yi Y, Wang Z, Li M, Zhu K, Ying G. Preparation and purification of monoclonal antibodies against chloramphenicol. Cytotechnology, 64, 157-163 (2012).

20) Chao Z, Tan M, Paudel MK, Sakamoto S, Ma L, Sasaki-Tabata K, Tanaka H, Shoyama Y, Xuan L, Morimoto S. Development of an indirect competitive enzyme-linked immunosorbent assay (icELISA) using highly specific monoclonal antibody against paclitaxel. $J$. Nat. Med., 67, 512-518 (2013).

21) Lu SY, Zhou Y, Li YS, Lin C, Meng XM, Yan DM, Li ZH, Yu SY, Liu ZS, Ren HL. Production of monoclonal antibody and application in indirect competitive ELISA for detecting okadaic acid and dinophytoxin-1 in seafood. Environ. Sci. Pollut. Res. Int., 19, 2619-2626 (2012). 
22) Li WH, Meng M, He FY, Wan YP, Xue HY, Liu W, Yin WW, Xu J, Feng CW, Wang SL, Lu X, Liu JT, Xi RM. Preparation of an anti-diethylstilbestrol monoclonal antibody and development of an indirect competitive ELISA to detect diethylstilbestrol in biological samples. Chin. Sci. Bull., 56, 749-754 (2011).

23) Alatengqimuge $\mathrm{Y}$, Yang XW, Zheng Y, Ma L, Lu W. LC analysis and pharmacokinetic study of pachymic acid after intravenous administration to rats. Chromatographia, 67, 807-811 (2008).

24) Yin $X, Q u$ C, Li Z, Zhai Y, Cao S, Lin L, Feng L, Yan L, Ni J. Simultaneous determination and pharmacokinetic study of polyphyllin I, polyphyllin II, polyphyllin VI and polyphyllin VII in beagle dog plasma after oral administration of Rhizoma Paridis extracts by LC-MS-MS. Biomed. Chromatogr., 27, 343-348 (2013).

25) Jahangiri S, Hatami M, Farhadi K, Bahram M. Hollow-fiber-based LPME as a reliable sampling method for gas-chromatographic determination of pharmacokinetic parameters of valproic acid in rat plasma. Chromatographia, 76, 663-669 (2013).

26) Spanakis M, Niopas I. GC-MS Simultaneous determination of enalapril and enalaprilat in human plasma: Application to a clinical pharmacokinetic study. Chromatographia, 72, 957-962 (2010).

27) Ying XX, Wang F, Cheng ZZ, Zhang WJ, Li HB, Du Y, Liu X, Wang SY, Kang TG. Pharmacokinetics of vitexin-4"-O-glucoside in rats after intravenous application. Eur. J. Drug Metab. Pharmacokinet., 37, 109-115 (2012).

28) Yang XM, Zhang XL, Chen YC, Liu F. LC method for determination of ginkgolic acids in mice plasma and its application to a pharmacokinetic study. Chromatographia, 69, 593-596 (2009).

29) Montagna M, Visai L, Di Comite A, Iommiello V, Avanzini MA, Bloise N, Stronati M, Ragazzi M. Development and validation of an enzyme linked immunosorbent assay for palivizumab serum determination. Int. J. Immunopathol. Pharmacol., 26, 503-510 (2013).

30) Chen HY, Zhuang HS, Yang GX, Ji XL. Development of a new polyclonal antibody for the determination of polychlorinated biphenyls in indoor air by ic-ELISA. Environ. Sci. Pollut. Res. Int., 20, 2244-2251 (2013).

31) Qu HH, Zhang GL, Zhao Y, Wan F, Sai JY, Wang Y, Kong H, Wang QG. Synthesis and identification of artificial antigen of geniposide. J. Beijing Univ. Tradit. Chin. Med., 36, 387-392 (2013).

32) Jin XL, Zhu XY. Puerarin in plasma TLC-UV density scanning measurement and its pharmacokinetics in rabbits. Chin. Pharm Bull., 7, 421-424 (1991).

33) $\mathrm{Yu} \mathrm{LR}, \mathrm{He} \mathrm{XY}$. Inclusion rate determination of puerarin- $\beta$ cyclodextrin using ultraviolet spectrophotometric. Chin. J. Spectr.
Lab., 29, 1930-1933 (2012).

34) Galfrè G, Milstein C. Preparation of monoclonal antibodies: strategies and procedures. Methods Enzymol., 73, 3-46 (1981).

35) North SM, Styles JM, Hobbs SM, Dean CJ. Monoclonal antibodies to rat sarcomata. I. Immunization procedures and source of lymphoid cells for hybridoma production. Immunology, 47, 397-405 (1982).

36) Johnson DR. Murine monoclonal antibody development. Methods Mol. Biol., 51, 123-137 (1995).

37) Goding JW. Antibody production by hybridomas. J. Immunol. Methods, 39, 285-308 (1980)

38) Weiler EW, Zenk MH. Iodinated digoxin derivatives with improved reactivity and stability, for use in radioimmunoassay. Clin. Chem., 25, 44-47 (1979)

39) Li H, Wu H, Shen C, Chen JY, Hu SL, Wu H. Comparative pharmacokinetics study after oral administration of geniposide in normal rats and adjuvant-induced arthritis rats by UPLC-MS/MS. Basic Clin. Pharmacol. Toxicol., 113, 294-299 (2014).

40) Wang F, Cao J, Hao J, Liu K. Pharmacokinetics, bioavailability, and tissue distribution of geniposide following intravenous and peroral administration to rats. Biopharm. Drug Dispos., 35, 97-103 (2013).

41) Kamath AV, Lu D, Gupta P, Jin D, Xin Y, Brady A, Stephan JP, Li $\mathrm{H}$, Tien J, Qing J, Damico-Beyer LA. Preclinical pharmacokinetics of MFGR1877A, a human monoclonal antibody to FGFR3, and prediction of its efficacious clinical dose for the treatment of $t(4 ; 14)$ positive multiple myeloma. Cancer Chemother. Pharmacol., 69, 1071-1078 (2012).

42) Tsai TH. Pharmacokinetics of pefloxacin and its interaction with cyclosporin A, a P-glycoprotein modulator, in rat blood, brain and bile, using simultaneous microdialysis. Br. J. Pharmacol., 132, 1310-1316 (2001).

43) Qu K, Dai J, Zhao L, Lu Y, Li B, Zhao X, Hou P, Zhang Y, Bi K, Chen $X$. A sensitive liquid chromatographic-mass spectrometric method for simultaneous quantification of six iridoid glycosides from Zhi-zi-chi Decoction in rat plasma and its application to a pharmacokinetic study. J. Pharm. Biomed. Anal., 78-79, 83-91 (2013).

44) $\overline{\text { Peng L }}$, Gao X, Song Y, Zhao L, Guo M, Su J, Zhang L, Liu H. A rapid and sensitive UPLC-MS/MS method for quantification of two caffeoylquinic acids and four main active components in rat plasma after an intravenous administration of Qingkailing injection and its application to a pharmacokinetic study. Biomed. Chromatogr., 28, 601-601 (2014). 